\title{
Addiction to Social Media and Attachment Styles: A Systematic Literature Review
}

\section{Maria Chiara D'Arienzo ${ }^{1} \cdot$ Valentina Boursier $^{1} \cdot$ Mark D. Griffiths $^{2}$ iD}

Published online: 18 April 2019

(C) The Author(s) 2019

\begin{abstract}
Web-based communication via social networking sites (SNSs) is growing fast among adolescents and adults and some research suggests that excessive SNS use can become an addiction among a small minority of individuals. There is a growing body of research that has examined the impact of attachment styles and its influence on internet addiction (more generally) and social media addiction (more specifically). Consequently, the present study systematically reviewed the evidence concerning internet/social media addiction and attachment style. A total of 32 papers published between 2000 and 2018 met the inclusion criteria following searches in the following databases: Scopus, Web of Science, PubMed, ProQuest, and Google Scholar. Findings demonstrated a significant positive association between insecure attachment (anxious and avoidant) and a more intensive and dysfunctional use of the internet and social media. Findings demonstrate that those with insecure attachment appear to use the social media sites as a way of replacing and compensating affection that is missing from those around the individual (e.g., family and peers). The findings suggest that the gratification model provides a useful framework to understand the effects of parental attachment on social media addiction. Limitations and future research are also discussed.
\end{abstract}

Keywords Attachment style · Anxious attachment - Social media addiction · Facebook use · Internet addiction

Mark D. Griffiths

mark.griffiths@ntu.ac.uk

Maria Chiara D'Arienzo

mariachiaradarienzo@gmail.com

Valentina Boursier

valentina.boursier@unina.it

1 Department of Humanities, University of Naples Federico II, Naples, Italy

2 Psychology Department, Nottingham Trent University, 50 Shakespeare Street, Nottingham NG1 4FQ, UK 
The use of the internet is now almost ubiquitous in many countries, particularly among adolescents and young adults (Kuss et al. 2014). The internet and the activities that can be done on it help people in different ways, such as connecting people with each other or providing easy access to different types of information. New forms of social interaction have recently emerged and some scholars have claimed that it is easier for individuals to be engaged in unhealthy and dysfunctional behavior (Soh et al. 2014) including potential addiction to social media (Kuss and Griffiths 2017). As stated long ago by Griffiths (2000), these online activities can become excessive, leading to deleterious behaviors in a minority of individuals. As of 2017, there were 2.78 billion active social media users worldwide and daily social media use had a higher rate than the year before. At present, the average daily use of social media is estimated to be $135 \mathrm{~min}$ per day, an increase of $9 \%$ from the previous year (126 min per day) (Statista 2017).

Compared to other traditional forms of addiction, the internet is not a substance, and has therefore been conceptualized as a behavioral addiction (Griffiths 2005). Its consumption when excessive may result in negative outcomes and become addictive (Griffiths et al. 2016) especially among a minority of adolescents and young adults (World Health Organization 2011). Such technological addictions (Griffiths 1996a), as noted by Soper and Miller (1983), are "like any other behavioural addiction, and consisted of a compulsive behavioural involvement, a lack of interest in other activities and physical and mental symptoms when attempting to stop the behaviour" (p. 40). In order to define and identify which types of behaviors may be considered as an addiction, Brown (1993) used six criteria, later extended by Griffiths (1996b, 2005). More specifically, in relation to social media use, these are:

- Salience: This refers social media use being the single most important thing in the individual's life both cognitively and behaviorally.

- Mood modification: This refers to social media use being used to consistently and reliably change an individual's mood state.

- Tolerance: This refers to the amount of social media use building up over time so that longer periods spent engaged in social media use are needed to get the desired mood modifying effects.

- Withdrawal symptoms: This refers to both physiological and psychological effects that occur when reducing or discontinuing use of social media.

- Conflict: This refers to social media use compromising and damaging interpersonal relationships, negatively impacting on occupational and/or educational activities, and creating intrapsychic conflicts (e.g., subjective loss of control).

- Relapse: This refers to the tendency to re-establish addictive social media behaviors after a period of abstinence.

\section{The Present Research in Context}

Scientific interest in behavioral addictions has previously examined a variety of factors related to such behavior. A lot of the empirical literature on behavioral addiction has focused on personality traits. Although the results across studies are not always in agreement, extraversion, shyness, and self-esteem are three factors often examined. Extraversion, in particular in the case of adults, is positively related to both SNS use and to addictive tendencies (Kuss and 
Griffiths 2011; Ho et al. 2017). These results suggest that extraverts need a higher level of stimulation that can be obtained by social media use (Wilson et al. 2010). Similar results have been found in undergraduate students high in shyness who prefer spending time online than offline (Orr et al. 2009). Online interactions can be very appealing for those individuals with social anxiety (Boute et al. 2009) and depression symptoms (Andreassen et al. 2016).

A study by Tang et al. (2016) adopted Saucier's (1994) Mini-Markers Scale to assess the Big Five personality traits. They showed that neuroticism was associated with internet addiction. Such individuals usually have anxiety about social relationships and online social media gives them the opportunity to be in touch with others (Blackwell et al. 2017) and to be reassured (Kandell 1998). Narcissism is another factor largely studied in relation to social networking activities and an association between narcissism and social media addiction has been demonstrated (Andreassen et al. 2017; La Barbera et al. 2009). Here, individuals seek a large audience in which they are visible and collect "likes." A recent study by Longstreet and Brooks (2017) investigated the contribution of life satisfaction. Results indicated that life satisfaction was inversely related to social media addiction. When the satisfaction level rises, social media addiction decreases. These results suggest that social media is often used as a surrogate for happiness.

There is a growing body of research that has examined the impact of attachment styles and its influence on internet addiction (more generally) and social media addiction (more specifically). The present paper systematically reviews the existing studies related to attachment styles contributing to Internet and social media abuse. It was carried out to better understand the relationship between attachment styles and addiction in general, and to examine the relationships between attachment styles and Internet addiction (and more specifically social media addiction). Based on previous literature examining attachment and addiction more generally, attachment theory appears to be a good theory in explaining specific aspects of social media engagement. For instance, attachment styles appear to influence time spent online and they can be used as frameworks to understand the reasons that drive social media usage. Risky behaviors have already been associated with attachment styles, and could represent a risk and predictive factor for addictive behaviors (Flores 2004).

\section{Attachment Theory}

The first pioneering study on attachment theory was by Bowlby (1958). He defined attachment as the first and most important relationship that children have with their caregivers (often the mother but not necessarily). However, as noted by Cohen (1974), the attachment figure is unique, and must provide specific relational and emotional responses (Weinraub et al. 1977). Until the 1950s, it was believed that children repeatedly sought their attachment figure merely for survival reasons. In contrast, and relying on Harlow's influential work (Harlow and Zimmermann 1959), Bowlby demonstrated that the affectional tie that individuals develop between themselves and another specific person is not solely based on food, safety, and other survival needs. As a result, human beings need something more: love, affection, and acceptance (Obegi and Berant 2010). Thus, as social animals (Weinraub et al. 1977), individuals are driven by a primary and instinctive tendency to seek out relationships (Schaffer and Emerson 1964).

This finding created interest about the different ways in which attachment can develop among individuals, and Ainsworth and Bell's (1970; Ainsworth et al.1978), Ainsworth et al. 
(2015) work on this matter is worth noting. They identified three main attachment styles (with Main and Solomon 1990 later identifying a fourth). The first style is secure attachment, linked to a sense of worthiness (Bartholomew and Horowitz 1991). The second style is insecure avoidant, usually referred to children deeply independent from the attachment figure both emotionally and physically (Behrens et al. 2007). The third style is insecure-ambivalent (also called anxious). Here, children have untrustworthy expectations about the otherness (Bartholomew and Horowitz 1991); they exhibit dependent and rejecting behaviors at the same time (McLeod 2008). Finally, the disorganized and dismissing style is related to those children who maintain a sense of independence from an attachment figure (Main and Solomon 1990). Despite those four discrete styles, more recently, research has tended to opt for a dimensional model of attachment (Brennan et al. 1998).

Although attachment styles play a fundamental role in childhood, they also provide the script for future close relationships. Memories, cognitive scripts, and emotions associated with a specific style and create an internal working model of self and others (Bowlby 1988). It can be assumed that repeated contact with appropriate others at any time in their lifetime can lead to the formation of an attachment, but it will be often influenced by the past relationships (Bowlby 1979). Thus, these internal "programmed" patterns shape an individual's way of being in a relational environment (Obegi and Berant 2010). Consequently, in a way analogous to physiological homeostasis, the attachment system can be thought as a mechanism able to create a fixed distance-accessibility to others thanks to advanced methods of communication (Bowlby 1969, 1973, 1982).

\section{Addiction as an Attachment Disorder}

In the domain of interpersonal relationships, attachment styles are adopted as a framework to describe infant-caregiver interactions. These interactions, as noted above, also represent the script for future close relationships. Furthermore, attachment theory claims that individuals are unable to regulate their affective state alone (see Flores 2004). This need, identified as "selfobject need," can be satisfied (or not) by external figures (Kohut 1971). According to addiction treatment specialists, there is an inverse relationship between addiction and healthy attachment styles. Consequently, Flores (2004) interpreted addiction as an attachment disorder, as a non-adaptive and late transition in young adulthood (Höfler and Kooyman 1996). Addiction is usually considered as a disorder in self-regulation, and addicted individuals are characterized by unsuccessful attempts at self-repair (Flores 2004). For instance, many authors studying substance abuse state there is a strong relationship between attachment and drug consumption among adolescents (Becoña et al. 2014). Consequently, the family is rightly identified as a protective factor in improving the abilities for dealing life's stressors (Mikulincer and Shaver 2007).

Experiences of primary deprivation leave individuals looking for something in the outside world that can replace a missing part "inside" of themselves. It appears that drug use can fulfill deficiency in intimacy (Flores 2004), giving an unrealistic feeling of having a secure base (Höfler and Kooyman 1996). However, as stated by many authors, the same goes for nonsubstance-related addictions (Estévez et al. 2017). The "self-object needs" (Kohut 1971) are therefore replaced in different ways: with a drug, an activity (e.g., social media use), an object, or any distraction that can help overcome the feeling of emptiness (Flores 2004). A higher risk for addictive behaviors, in substance and in non-substance abuse, is present in cases of 
avoidant and ambivalent attachment styles (Valizadeh et al. 2017). Consequently, it is not difficult to imagine how dysfunctional behaviors and negative emotions (e.g., maladaptive coping strategies and low social skills) can increase the risk of substance and/or non-substance abuse (Dozier et al. 1998). Consequently, the present paper attempted to systematically review all research to date that has examined the role of attachment style on addiction to the internet and/or social media.

\section{Methods}

A systematic review was conducted using the following databases: Scopus, Web of Science, PubMed, ProQuest, and Google Scholar for papers published from 2000 to 2018. Even though most studies concerning this topic were published in the past decade, a longer period was chosen because social networking sites (SNSs) date back to 1997. In order to shape the search, the advanced searches combined the following keywords: social media addict* or social media and attachment, or attachment styles or attachment theory, in addition social network* or social networking addiction and attachment styles or attachment theory. As for the simple searches, the keywords were social media, social networking addiction, Internet or Facebook use, attachment, attachment style, and attachment theory. Papers in three different languages were collected: Italian, English, and Spanish (those languages in which the authors were proficient). The databases were searched between March and May 2018. A total of 378 records were identified. The papers not meeting the inclusion criteria and duplicates were excluded. Because adolescents and adults are more likely to incuraddiction (WHO 2011), only those papers where the age ranges were over 13 years were included in the review. Dissertations and conference proceedings were also excluded from the review.

\section{Results}

A total of 32 papers were retrieved for the systematic review that met the initial inclusion criteria (see Table 1 for a complete list as well as all the main findings and methodological issues). Apart from a few studies that examined SNS usage via statements or questionnaire rather than using a psychometric scale (e.g., Longua Peterson et al. 2017), the majority of the studies utilized original, revised, or translated versions of validated online use scales. The present review examined internet use, social media use, and SNS use, but they are not the same. Studies examining internet use were only considered for inclusion in the present review if the use was linked to social communication (consequently, studies relating to online gaming and online gambling were excluded).

The main diagnostic assessment instruments for assessing the different types of internet abuse in the evaluated studies were the Internet addiction Test (IAT; Young 1998), Problematic Internet Use Scale (PIUS; Ceyhan et al. 2007), Adolescent Pathological Internet Use Scale (APIUS; Lei and Yang 2007), and the Bergen Social Media Addiction Scale (BSMAS; Andreassen et al. 2012). The main instruments used to assess attachment styles in the evaluated studies were the Experiences in Close Relationships Scale (ECR; Brennan et al. 1998), Attachment Style Questionnaire (ASQ; Feeney et al. 1994), and Relationship Scale Questionnaire (RSQ; Griffin and Bartholomew 1994). 


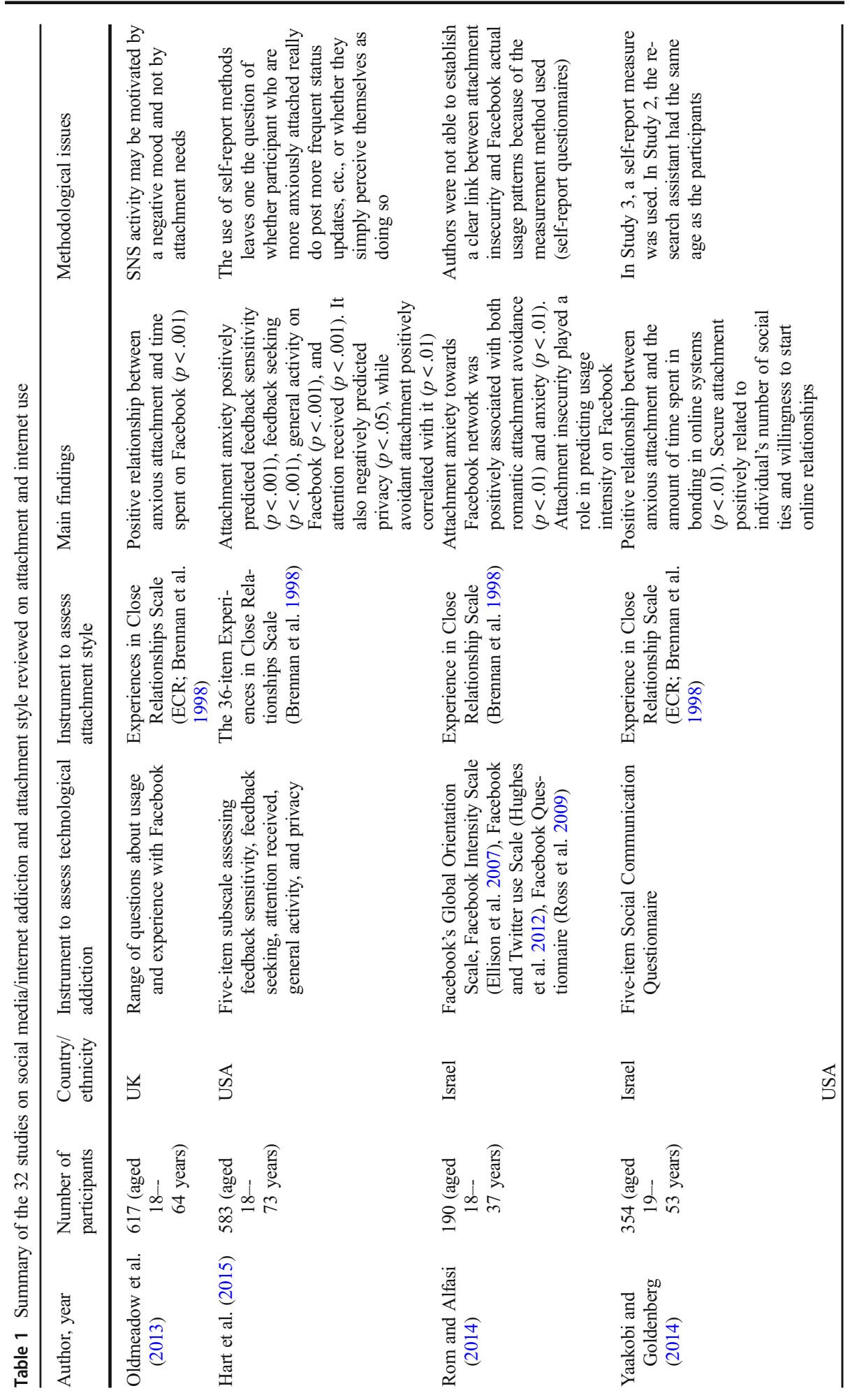




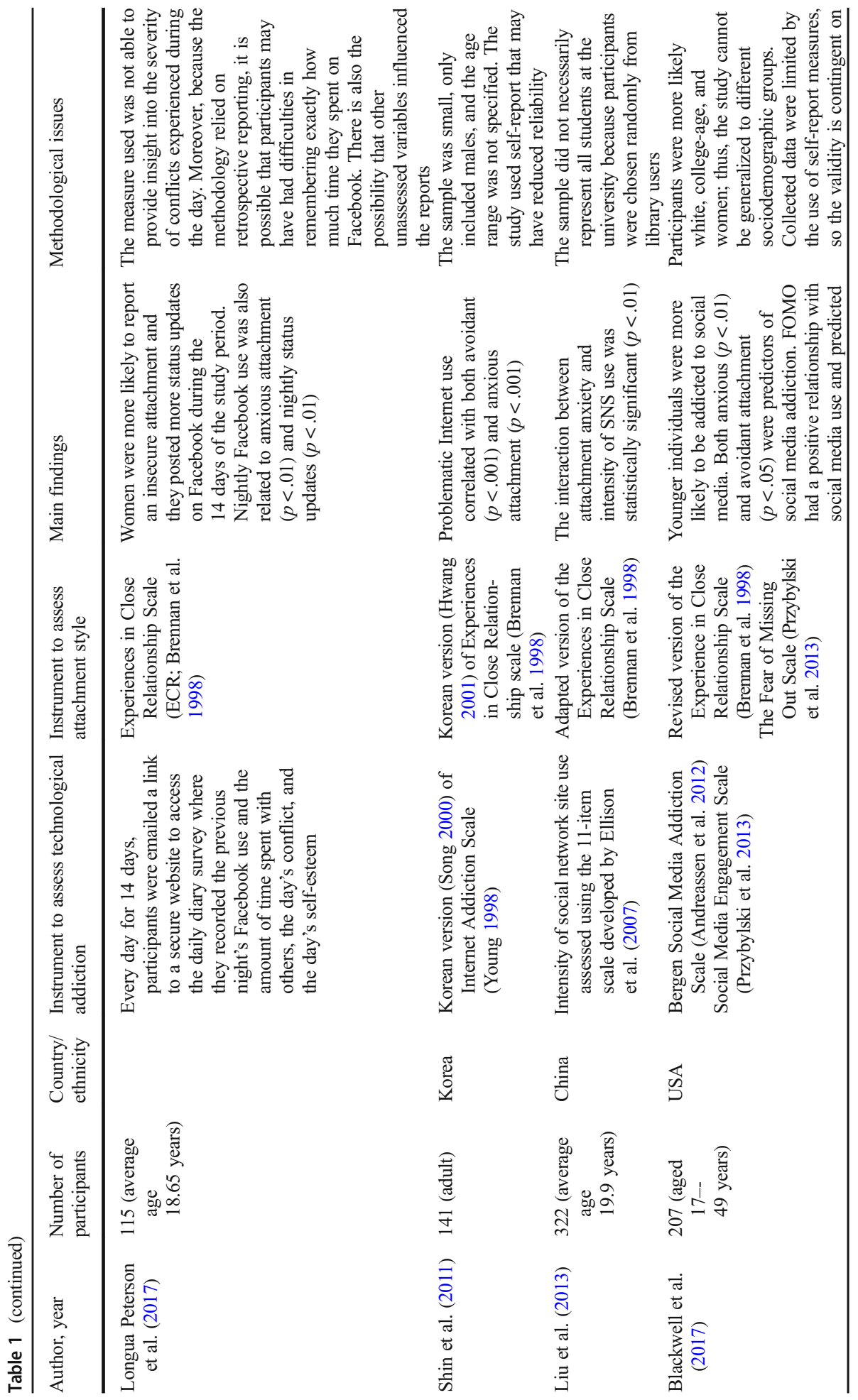




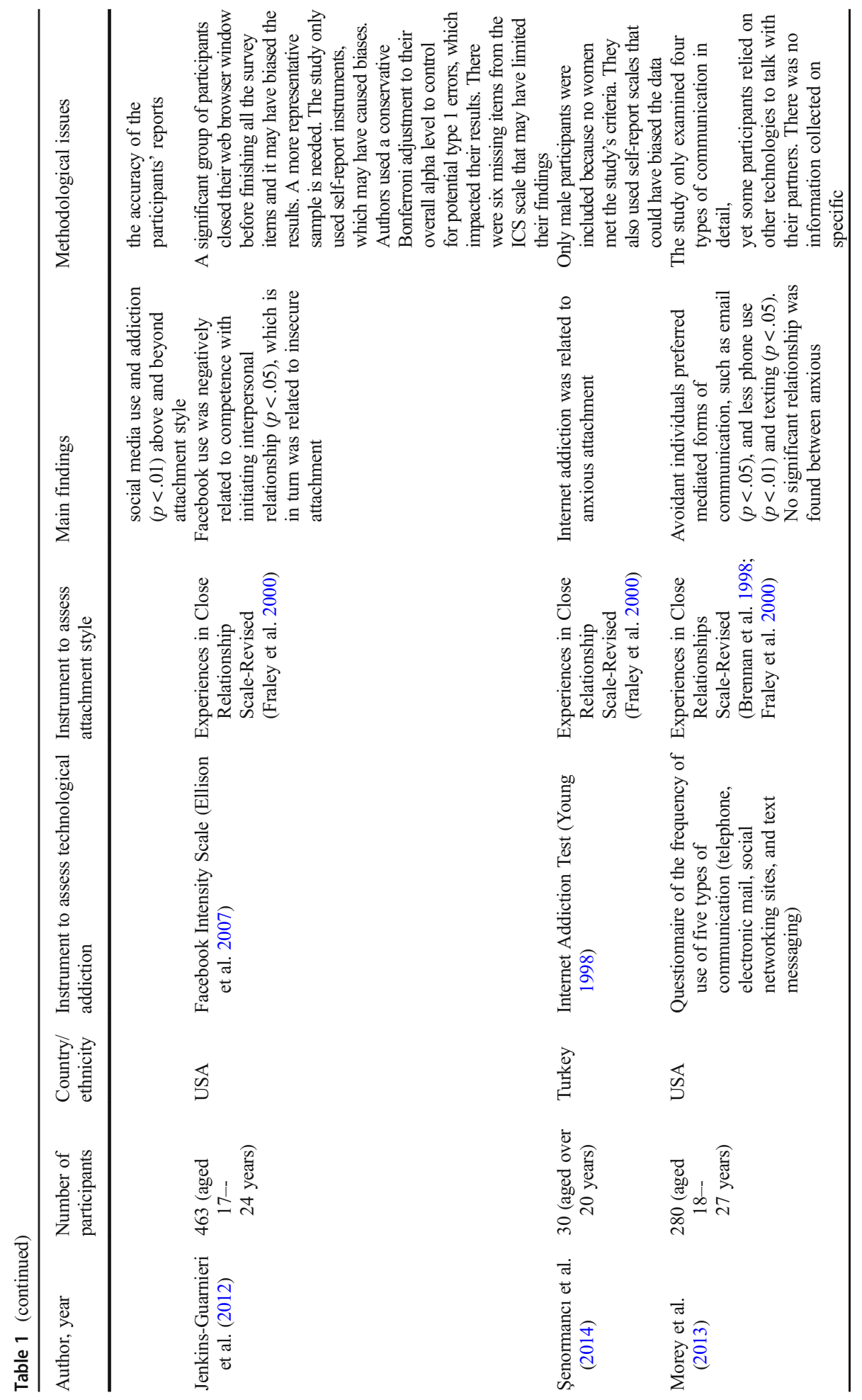




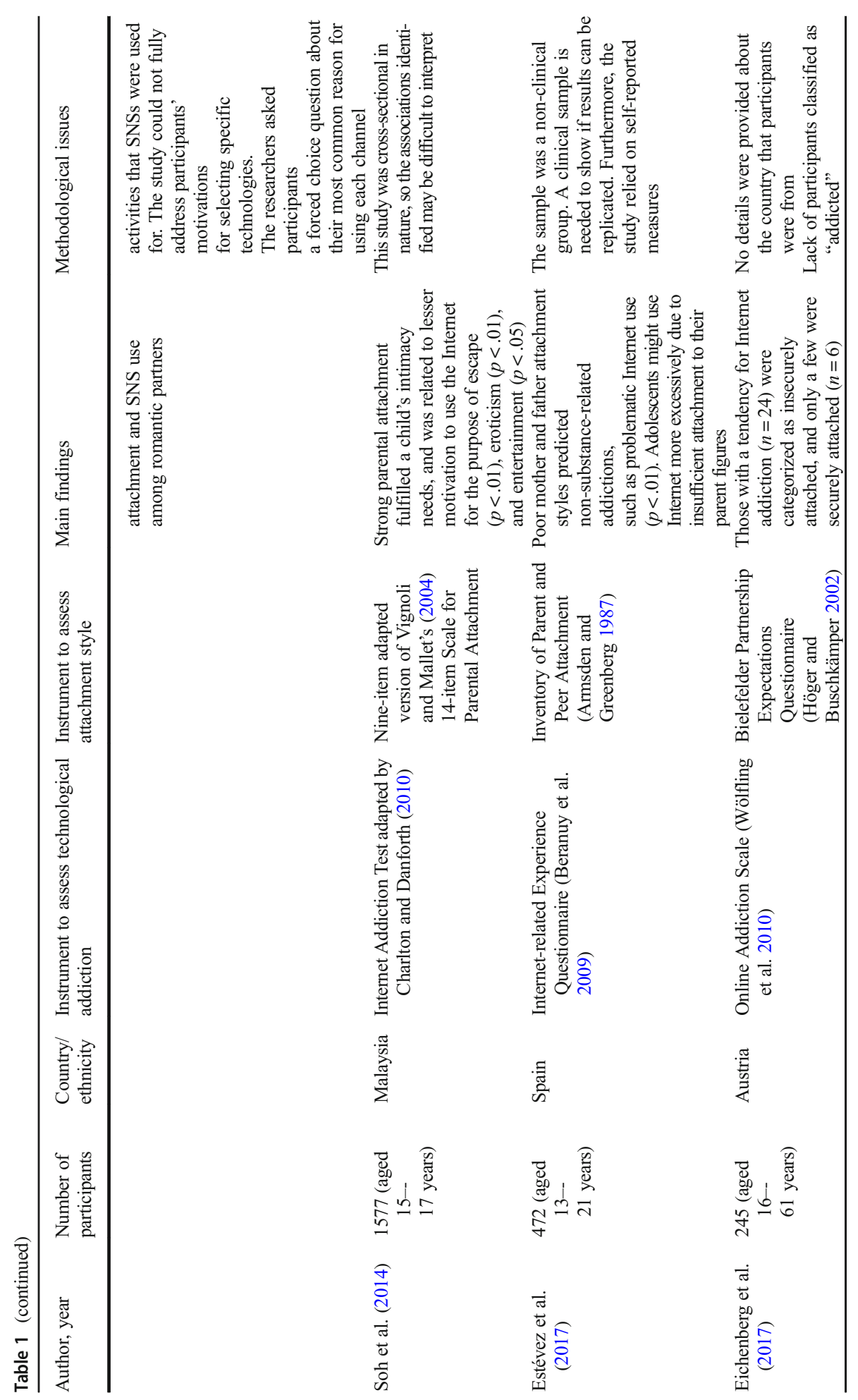




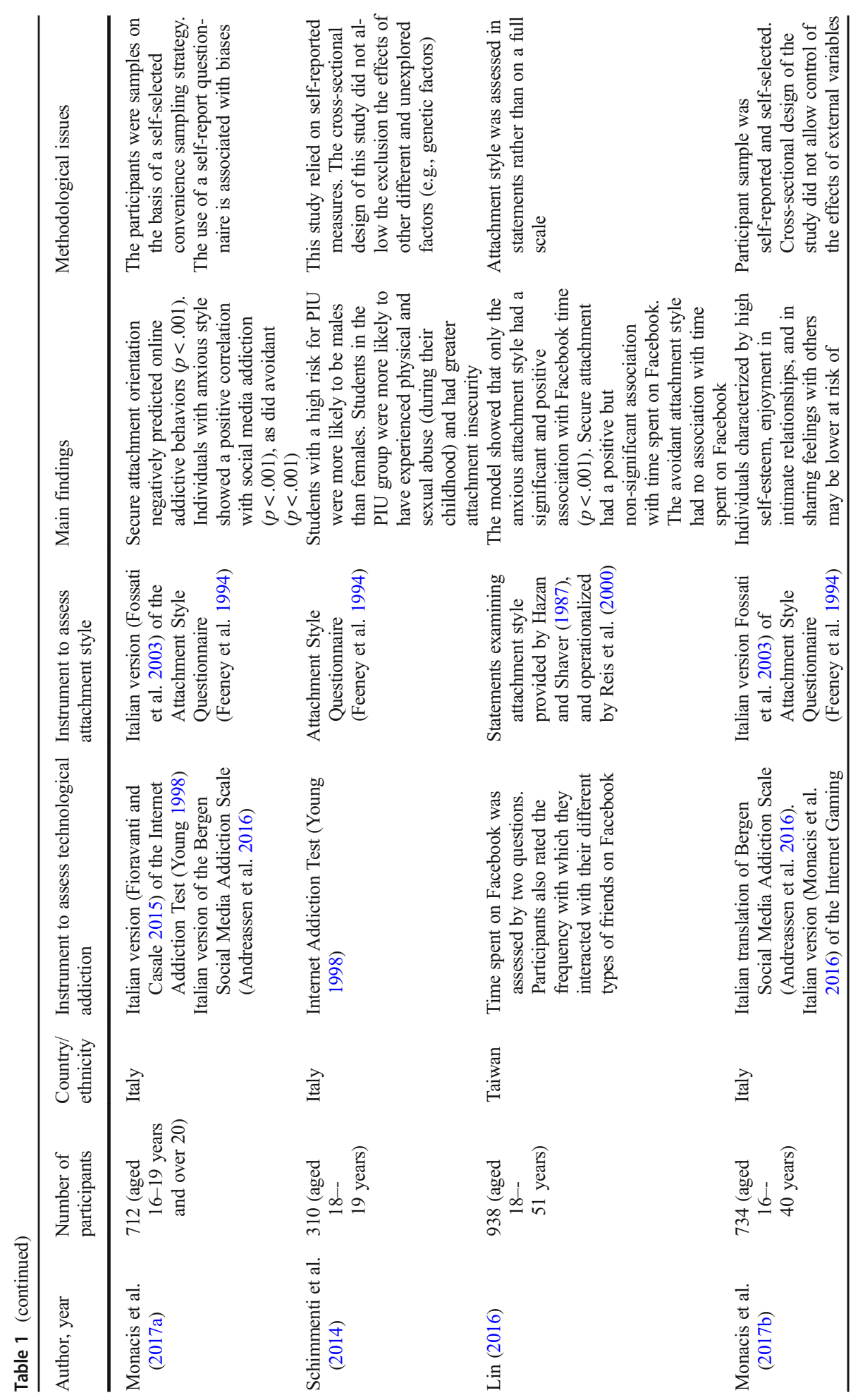




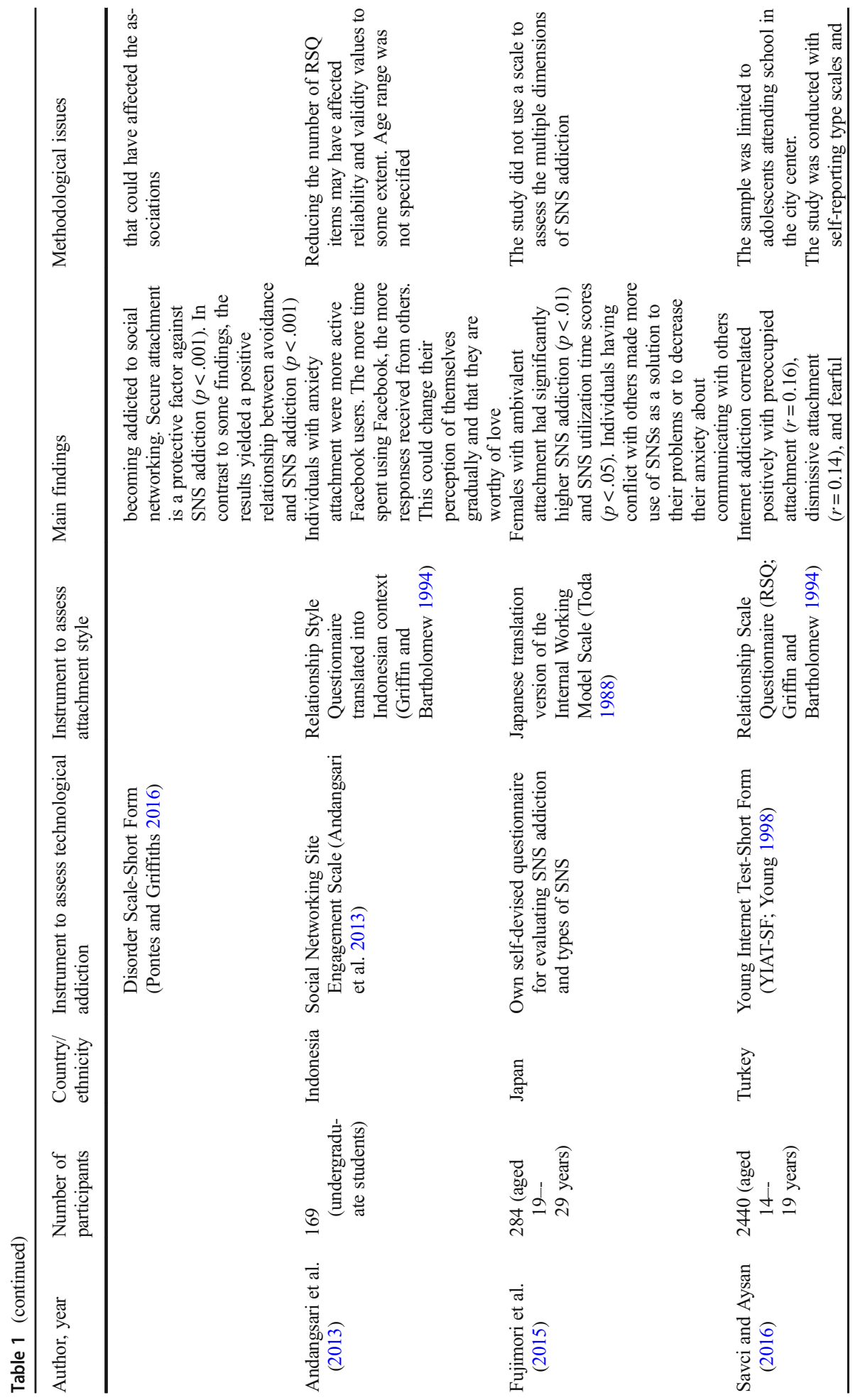




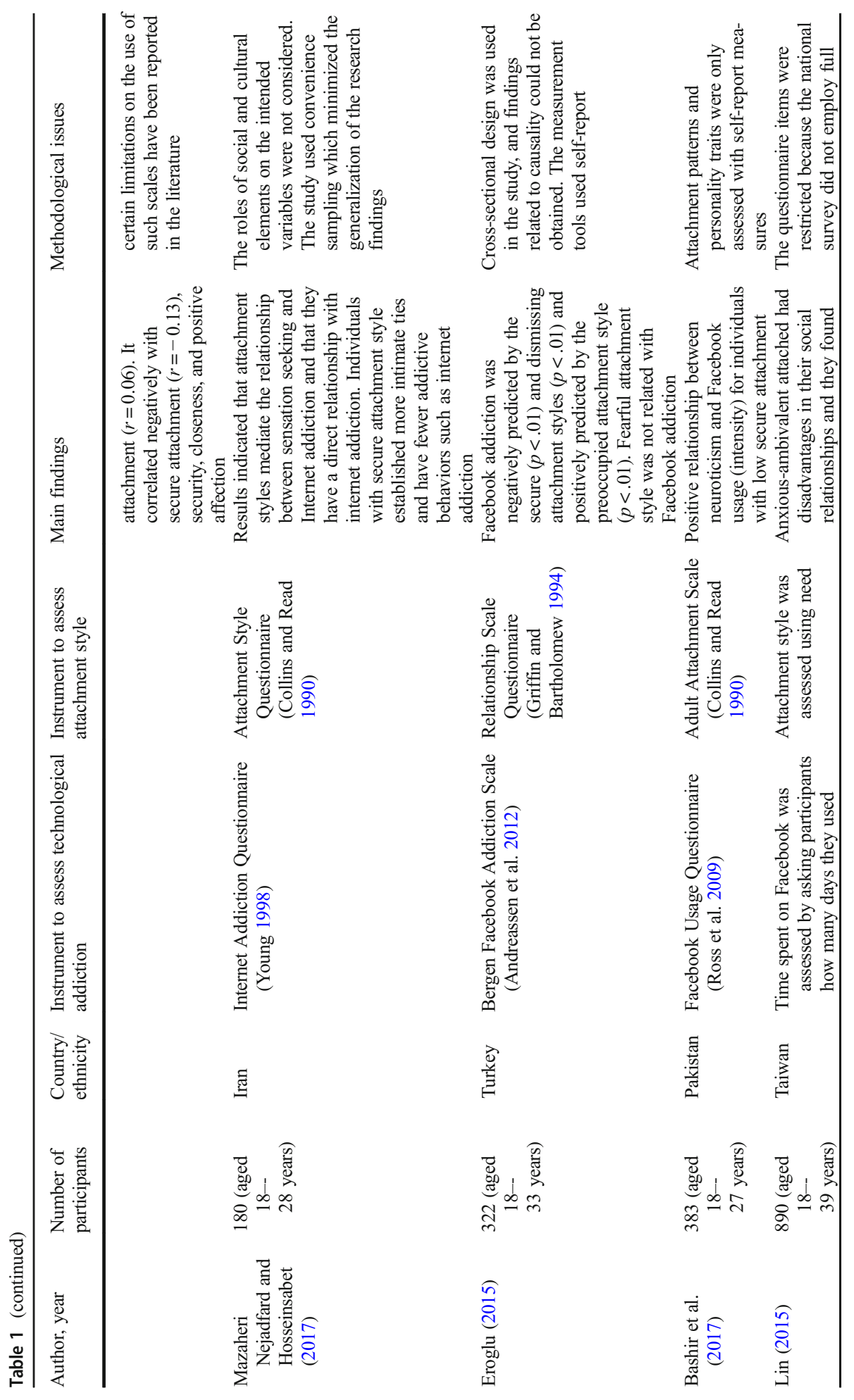




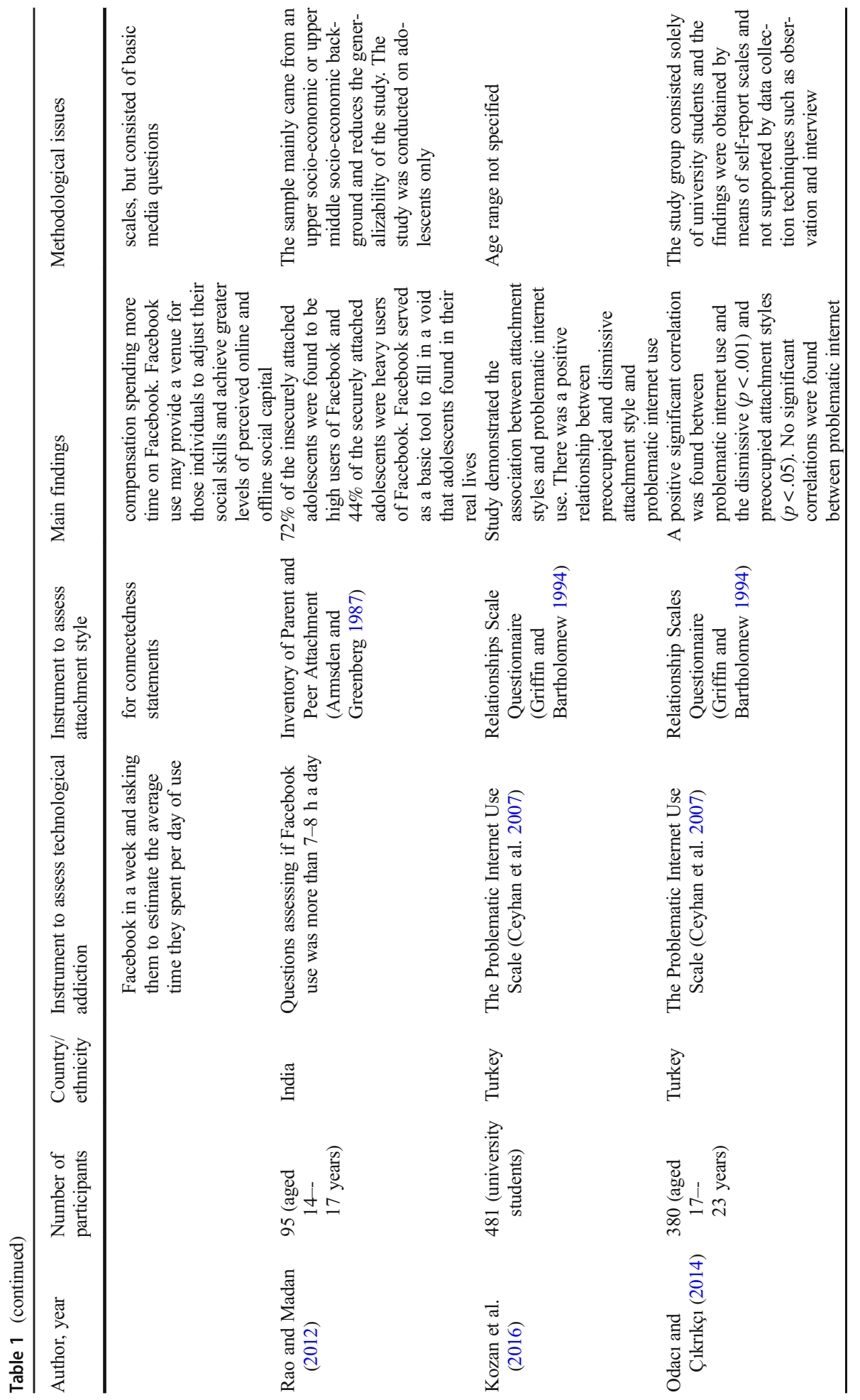




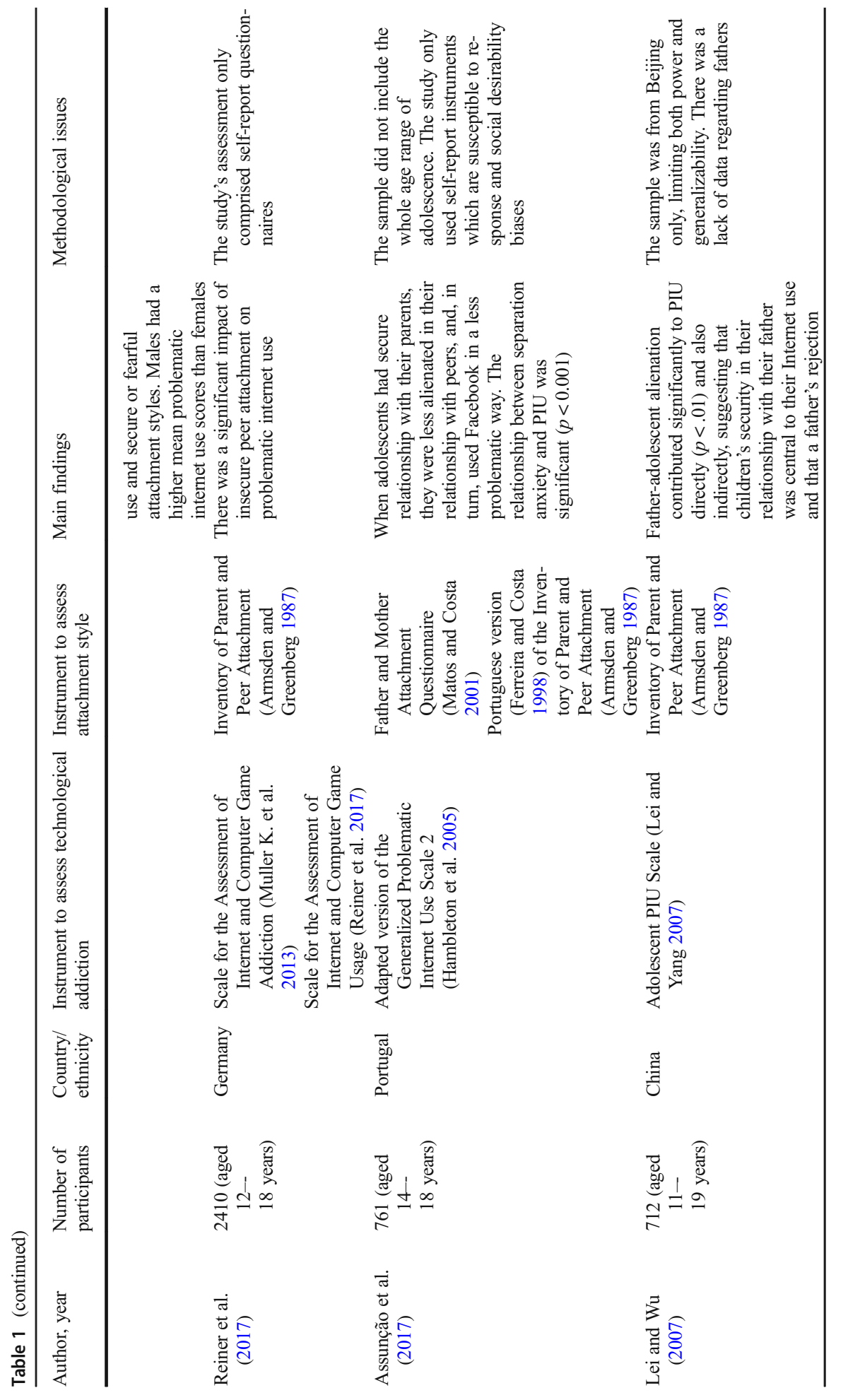




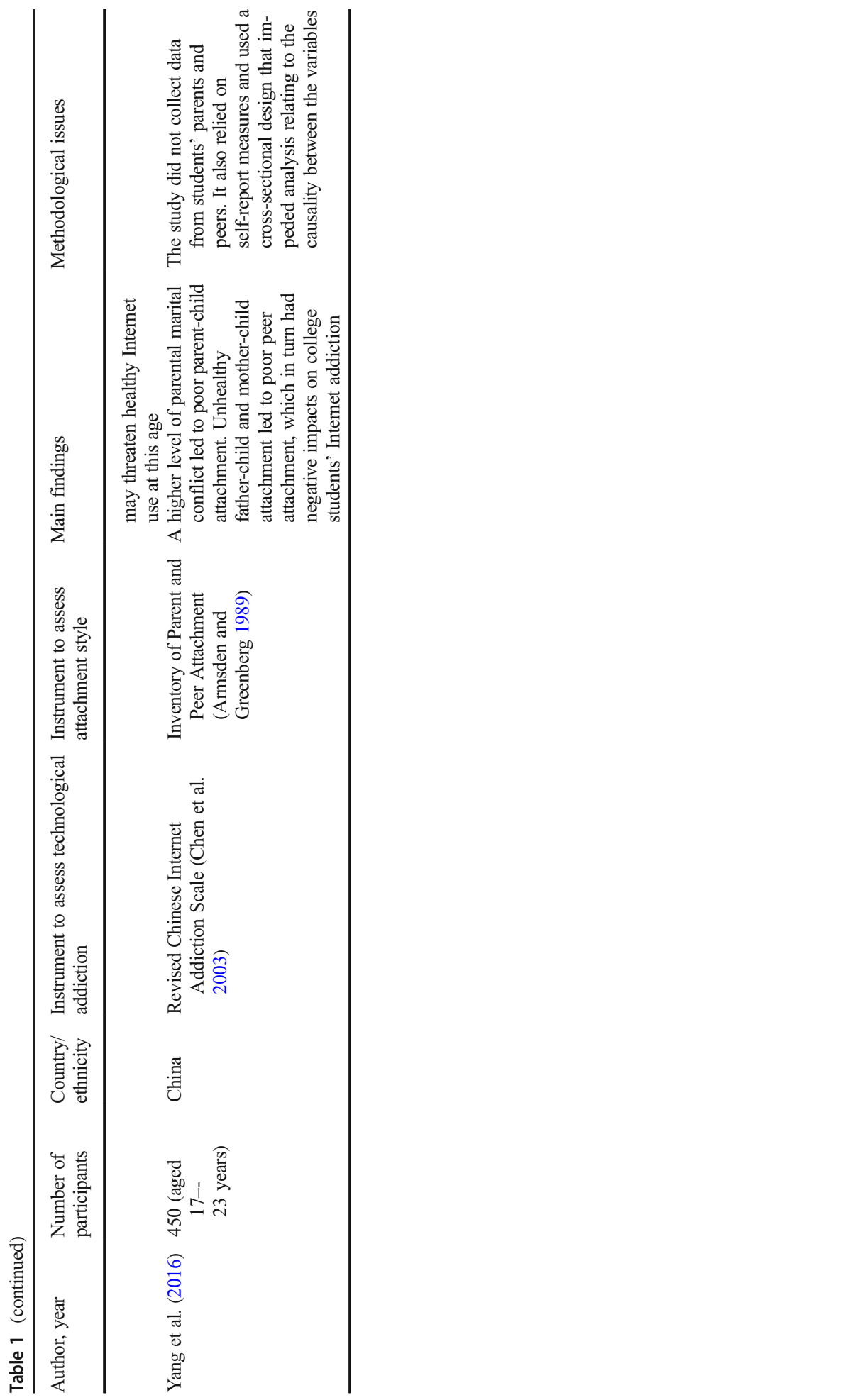




\section{The Role of the Attachment Theory in the Most Used Scales}

In this systematic review, the ECR (Brennan et al. 1998) was used in seven studies to assess attachment in the context of close adult relationships. Its revised version (ECR-R; Fraley et al. 2000) was used in four additional studies (therefore, the ECR was the most frequently used scale in the studies evaluated in the present review). The sample sizes range from 30 (SSenormanc1 et al. 2014) to 617 participants (Oldmeadow et al. 2013). The ECR/ECR-R assesses the two major dimensions of attachment (anxiety and avoidance; i.e., anxiety about abandonment or being afraid of disapproval). Those two dimensions were found to be related to different factors, such as Facebook intensity and experience, its engagement, social media addiction, the intensity of SNS use, internet use, and internet addiction.

In terms of usage, Oldmeadow et al. (2013) found a positive association between a higher attachment anxiety and a more intensive use of Facebook. Liu et al.'s study (2013) also reported a positive relationship between anxious attachment and high SNS use. Being anxiously attached was associated with decreased perceived interpersonal competency. Such individuals were therefore more likely to initiate online relationships, which may explain their high use of Facebook (Jenkins-Guarnieri et al. 2012) and addiction to it (Eroglu 2015). Yaakobi and Goldenberg (2014) reported a high positive relationship between that attachment style and the amount of time spent in bonding in such systems. The same study also found that anxious attachment negatively predicted the number of friends.

Other studies have reported that anxious attachment is positively associated with high nightly time on Facebook, nightly status update (Longua Peterson et al. 2017), and to general activity on Facebook (Hart et al. 2015; Andangsari et al. 2013). A higher amount of time spent online can lead to pathological behavior, as found in the study by Şenormanc1 et al. (2014). Their Turkish sample of patients with internet addiction reported daily Internet use of $7.5 \mathrm{~h}$, and was related to anxious attachment. Oldmeadow et al. (2013) also found significant associations with different aspects of Facebook experience. For instance, anxious attachment was strongly related to Facebook comfort seeking, and that drives Facebook use particularly when feeling negative emotions. Similar results were reported by Hart et al. (2015) who reported a positive correlation between attachment anxiety and feedback seeking, and a positive relationship with attention received.

Attachment avoidance has been reported to have no significant relationship with Facebook attachment (Oldmeadow et al. 2013; Andangsari et al. 2013) and Facebook addiction (Eroglu 2015; Lin 2016). Furthermore, participants high in attachment avoidance have been found to be less likely to be happy about their Facebook profile (Oldmeadow et al. 2013). This attachment style positively predicted privacy ${ }^{1}$ (Hart et al. 2015), and was negatively (but not significantly) related to nightly status updates on Facebook (Longua Peterson et al. 2017), and to online capital ${ }^{2}$ (Lin 2015). Avoidant individuals were less to likely to be a social hub because they rarely initiated a social relationship or received a friend request by others (Yaakobi and Goldenberg 2014).

\footnotetext{
${ }^{1}$ Privacy is the tendency to protect personal information. In particular, an item that investigates this aspect in online interactions is "I only send friend requests to people who I have met before in person."

${ }^{2}$ The term "online capital" is based on "social capital" and is a form of cultural capital built on online social networks. It includes the inclinations that arise from these networks to do thing for each other (cooperation, trust, and reciprocity)
} 
Contrary to these results, Monacis et al. (2017a) found that avoidant attachment significantly predicted social media addiction, and Savc1 and Aysan (2016) showed that it also predicted Internet addiction. Problematic internet use has been correlated with both being anxious (Assunção et al. 2017; Mazaheri Nejadfard and Hosseinsabet 2017; Reiner et al. 2017; Savc1 and Aysan 2016; Shin et al. 2011) and having avoidant attachment (Kozan et al. 2016; Odacı and Çıkrıkçı 2014; Shin et al. 2011). Blackwell et al. (2017) reported that both anxious and avoidant attachment were correlated with social media addiction, and that was before they included "fear of missing out" (FOMO; Przybylski et al. 2013) in their model. These results are in line with research showing an association between insecure attachment style and internet addiction (Shin et al. 2011; Şenormanc1 et al. 2014; Monacis et al. 2017a). Therefore, it is assumed that avoidant attachment is associated with social media addiction only when individuals are also high in attachment anxiety. Such individuals can use social media to feel connected to others but not actually engage in social interaction (Blackwell et al. 2017).

Results from Morey et al.'s (2013) study confirmed that there was a different engagement between anxious-avoidant attachment and forms of communication (such as inperson communication, smartphone use, texting, email, and SNS usage). They demonstrated that romantic partners with an anxious attachment preferred tools that allowed for greater intimacy and immediate response. In contrast, avoidant individuals, as previous studies have shown (Hart et al. 2015), were more likely to prefer mediated forms of communication, such as email, and less likely to be associated with mobile phone use and texting (Morey et al. 2013).

\section{The Influences on Internet Engagement and Its Most Used Assessment Tools}

Monacis et al. (2017a) noted that internet addiction may be considered as an umbrella construct, which contains addictive online activities such as social media addiction. Authors have reported that secure attachment orientation negatively predicts social media addiction (Monacis et al. 2017a), and internet addiction (Eichenberg et al. 2017; Monacis et al. 2017a). This is in line with the negative association found between secure attachment, Facebook time, and Facebook addiction (Bashir et al. 2017; Eroglu 2015; Rao and Madan 2012). Moreover, it has been assumed that stronger parental attachment is related to lesser need to use the internet (Yang et al. 2016) for the purpose to escape (Soh et al. 2014), and studies have concluded that it may be considered a protector factor (Eichenberg et al. 2017; Savc1 and Aysan 2016; Mazaheri Nejadfard and Hosseinsabet 2017; Kozan et al. 2016). Children's security in their relationship with parents is central to their Internet use (Assunção et al. 2017).

It is important there is a bond whether it is with the mother (Estévez et al. 2017 or the father (Lei and Wu 2007) because any secure bond is better than no bond at all. A good relationship with one parent is enough to lead to positive outcomes if it is based on trust, security, and mutual understanding. Moreover, students experiencing pathological internet use are more likely to report childhood experiences of psychological and sexual abuse (Schimmenti et al. 2014). The same paper also found that youth who are particularly preoccupied with their offline relationships may use online environments as a virtual retreat and as a way of protecting themselves from feelings of loneliness, and their fears concerning offline interactions. 


\section{Discussion}

The aim of the present paper was to review any associations between attachment and internet addiction (and particularly social media addiction). The results suggest that social media addiction may relate back to earlier stages in individuals' lives. Research has demonstrated that growing up in a well-functioning family helps individuals to form a mature healthy personality (Șenormanc1 et al. 2014). In contrast, it appears that families' inability to form emotional bonds appear to contribute to addictive behavioral patterns (Șenormanc1 et al. 2014; Estévez et al. 2017). This suggests that addiction, and more specifically social media addiction, can stem from issues that originate in infancy or childhood. Overall, the results of the studies evaluated provide support for the association between social media addiction and two types of insecure attachment (i.e., anxious and avoidant). The paper first evaluated the findings concerning the relationships with Facebook, which is currently the most popular SNS used in the world. Depending on the type of attachment, individuals experience social media in different ways (Oldmeadow et al. 2013). The present review provides evidence that individuals high in attachment anxiety appear to use Facebook to alleviate their lack of attachment functioning.

\section{The Impact of Facebook Addiction}

Of the studies reviewed, it would appear that the majority of insecurely attached adolescents use Facebook after being admonished by their parents (e.g., in Rao and Madan's study [2012] an adolescent claimed: "Sometimes I try talking to my mother, but she always says she's too busy, so I end up logging onto Facebook and I talk to my friends instead"; p. 8). Consequently, it appears that using Facebook fulfills the need for care and affection, and replaces and compensates for missing affection from family members (Rao and Madan 2012). Using Facebook becomes a means for social compensation (Eroglu 2015). However, individuals have different ways to accomplish the innate need for relatedness, and attachment style can influence its satisfaction (Lin 2016). For instance, high secure and anxious attached individuals achieve such a need by spending more time on Facebook, while those avoidant attached do not (Lin 2016).

Research indicates that individuals who are anxious about being alone and have a strong need for reassurance spend more time on Facebook (Oldmeadow et al. 2013; Rom and Alfasi 2014). The more time they spend on Facebook, the more feedback and responses they receive from others. This also provides the opportunity to change their perception about themselves, and to be aware of being worthy of love (Andangsari et al. 2013). Those individuals who are characterized by a high attachment anxiety engage in social media use when they experience negative emotions. For example, when in doubt and in fear about a partner's commitment, individuals use reassurance seeking as a strategy to cope with their insecurities (Rom and Alfasi 2014). However, the attention-seeking is core part of the anxious attached individuals' hyper-activation strategy (Rom and Alfasi 2014). Thus, they use Facebook intensely (i) as a means to develop and maintain their relationships (Andangsari et al. 2013; Assunção et al. 2017; Estévez et al. 2017; Liu et al. 2013; Longua Peterson et al. 2017; Rao and Madan 2012; Rom and Alfasi 2014;), (ii) for facing the fear of abandonment (Yaakobi and Goldenberg 2014), (iii) to cope with rejection (Jenkins-Guarnieri et al. 2012), and (iv) to alleviate negative views of themselves (Andangsari et al. 2013).

The studies also indicate that Facebook is used by individuals to alleviate their feelings of being alone (Oldmeadow et al. 2013; Longua Peterson et al. 2017), and can be perceived as a 
community to which they can belong (Rom and Alfasi 2014; Longua Peterson et al. 2017). Using social media provides instant access to many individuals and it appeals to users high in attachment anxiety (Oldmeadow et al. 2013; Monacis et al. 2017b). Such individuals perceive Facebook as a safe haven (Rom and Alfasi 2014), a comfortable platform for seeking sense of belonging, and/or for articulating their opinions (Rom and Alfasi 2014). Since these individuals are sensitive to criticism (Hart et al. 2015), Facebook may also help them to avoid conflict, excessive closeness with others (Liu et al. 2013), and increase their connection strategies (Jenkins-Guarnieri et al. 2012). In this way, it appears that they may gain more real-world social benefits from social media use (Hart et al. 2015). In addition, Facebook anonymity makes it easier for individuals to initiate relationships (Jenkins-Guarnieri et al. 2012), thus facilitating potentially addictive use in a small minority of individuals (Monacis et al. 2017b).

Unfortunately, research indicates that the relationship between having trouble in interpersonal relationships and having a high engagement online constitutes a vicious cycle for those individuals, because they will be at high risk of social withdrawal (Shin et al. 2011). Furthermore, it is also possible that Facebook only provides a short boost to well-being, and that the positive effects dissipate once participants go offline (Hart et al. 2015). This may partially explain why a social networking site may form a compulsive habit for a small minority of individuals (Hart et al. 2015).

It also appears that individuals with anxious attachment are interested in how Facebook users perceive them (Oldmeadow et al. 2013), and they are more likely to be associated with general social media activity (time spent on Facebook, commenting, and liking behaviors), feedback sensitivity (i.e., sensitivity concerning online feedback), and feedback seeking on the site (Hart et al. 2015; Monacis et al. 2017b). They also spend a lot of time on Facebook because they feed on others' feedback (Hart et al. 2015). Facebook may also allow them to have a greater control over their self-presentation online (Oldmeadow et al. 2013; Yaakobi and Goldenberg 2014). Via the use of Facebook, it is possible to manipulate individuals to edit their self-portrayal and profile online, in an attempt to show an always perfect image of themselves (Oldmeadow et al. 2013). When posting a photograph or a post, anxious attached Facebook users constantly check if anyone has commented or liked them and is their way of "feeling alive."

As for the avoidant attachment style, no significant relationships were found regarding intensive Facebook usage (Hart et al. 2015; Lin 2015; Oldmeadow et al. 2013). Avoidant individuals are more introverted (Hart et al. 2015) and they do not want to rely on others because they do not trust others to be attached with (Andangsari et al. 2013). They do not seek attention on Facebook because they feel independent, and because the interaction with others may remind them of the way in which they were repeatedly neglected by their caregivers in the past (Andangsari et al. 2013). In attachment theory, attachment avoidance is related to an individual's hesitance to become close with others (Jenkins-Guarnieri et al. 2012). Moreover, it appears that Facebook does not have a significant impact on their attachment needs (Andangsari et al. 2013). Individuals high in attachment avoidance do not spend a lot of time on Facebook, and are less likely to hold a positive attitude about it. Interestingly, a significant positive relationship was found between this attachment style and evaluation concern (Oldmeadow et al. 2013). This means that although they have feelings of being self-sufficient, they still have a level of concern about how others view them.

Regarding securely attached individuals, they are usually sociable, expressive, and use Facebook in a positive way. Because they are characterized by high self-esteem and have good social skills (and thus intimate relationships), they appear to be at lower risk of becoming addicted to the internet generally and to social media specifically (Bashir et al. 2017; Eroglu 
2015; Monacis et al. 2017a; Odacı and Çıkrıkçı 2014; Rao and Madan 2012). They also have a stronger sense of control that gives them the opportunity to resist stressful conditions (Savc1 and Aysan 2016). When they need help, they ask for it, knowing that it is possible to rely on their friends and family. Their secure relationships with parents give them the power to explore the world without fear, and to feel worthy of love. This enables them to feel safe in sharing feelings with others and to construct secure relationships (Assunção et al. 2017). These results suggest that individuals who already have mature social skills gain greater and healthier functions via Facebook usage (Lin 2015). Therefore, these individuals act using more functional coping strategies (Bashir et al. 2017; Mazaheri Nejadfard and Hosseinsabet 2017; Savc1 and Aysan 2016) and are more protected against addiction to social media (Monacis et al. 2017b).

\section{The Influence of Internet Addiction}

As for attachment styles and internet addiction more generally, findings indicate that a stronger parental attachment is related to less motivation to use the internet to escape from everyday problems (Soh et al. 2014). Attachment to parents fulfills children's intimacy needs, giving them what they are looking for, and not forcing them to seek escapism (Mazaheri Nejadfard and Hosseinsabet 2017; Soh et al. 2014). Escapism appears to contribute to addictive behavior online (Soh et al. 2014). More specifically, secure individuals accept their own emotional needs (Estévez et al. 2017), while insecure individuals do not (e.g., anxious-avoidant). The more they think they cannot rely on others' support (Estévez et al. 2017), the more it leads to the avoidance of interpersonal relationships and they search for compensation via online engagement (Eichenberg et al. 2017; Estévez et al. 2017; Fujimori et al. 2015; Lei and Wu 2007; Savc1 and Aysan 2016; Yang et al. 2016). This finding is in line with research suggesting that childhood trauma (e.g., physical and sexual abuse) can be a risk factor for internet addiction (Odacı and Çıkrıçıı 2014; Schimmenti et al. 2014).

It appears that those deeply preoccupied about relationships may use the Internet as a type of self-therapy, a safe environment where they can find what they perceive as missing in the their day-to-day lives, such as emotional support (Savc1 and Aysan 2016; Schimmenti et al. 2014). On one hand, such "therapeutic means" (e.g., Facebook use) can optimistically lead insecure individuals to the path of secure attachment (Andangsari et al. 2013). In this way, insecurely attached individuals tend to withdraw from environment because they think that their self-efficacy is threatened (Eroglu 2015).

While the results presented here offer new insights into one risk factor for social media addiction, these studies have their limitations. One limitation is that the majority of the studies utilized self-report measures rather than actual behaviors. These methods raise the question of whether participants simply misperceive themselves. Thus, the accuracy of individual reports cannot be always guaranteed because these methods are subject to well-known biases (e.g., response biases, memory recall biases, social desirability biases). Future research will need to apply more sophisticated tools that are able to analyze personal profiles and features. In addition, all studies recruited samples that relied on a self-selected convenience sampling strategy (i.e., a biased sample with non-probability sampling).

Future research should focus on the relationship between avoidance and social media use because several of the collected coefficients approached significance. It would also be interesting to investigate what happens in the offline world after having gained more confidence through online social media use. Using social media may facilitate the development of social skills via the online medium. Consequently, using social media could lead to positive 
outcomes such as improved mood for individuals with different attachment styles. Another limitation is that the causal hypotheses and mediation models tested concerning attachment styles and social media engagement could not be confirmed because all the studies were crosssectional. Future research should be carried out longitudinally and could examine the alternative causal models (e.g., that social media engagement causes attachment anxiety). Different studies should also continue to examine FOMO as a significant variable to study in the relationship between social media addiction and attachment styles. Finally, more research should be conducted to determine the impact of other types of social media (other than Facebook use), and to confirm if the results presented here can be generalized to populations of different ages, such as older adults.

Despite all these limitations, the present review collated and evaluated important findings explaining individuals' reasons for using social media in relation to attachment. This knowledge can be positively used to better understand how individuals attempt to cope with problems and past feelings, and to help develop prevention programs and clinical interventions. Online social networking sites, such as Facebook, serve a basic human need and individuals use them to satisfy their attachment need. Thus, the findings presented here suggest that a gratification model provides a useful framework in which to understand the effects of parental attachment on internet and social media addiction (Soh et al. 2014). The actions (or rather inactions) of parents appear to actively influence and contribute to children's addiction to social media, and can greatly influence their later lives.

\section{Compliance with Ethical Standards}

Conflict of Interest The authors declare that they have no conflict of interest.

Ethical Approval All procedures performed in this study involving human participants were in accordance with the ethical standards of University's Research Ethics Board and with the 1975 Helsinki Declaration.

Informed Consent Informed consent was obtained from all participants.

Open Access This article is distributed under the terms of the Creative Commons Attribution 4.0 International License (http://creativecommons.org/licenses/by/4.0/), which permits unrestricted use, distribution, and reproduction in any medium, provided you give appropriate credit to the original author(s) and the source, provide a link to the Creative Commons license, and indicate if changes were made.

\section{References}

Ainsworth, M., \& Bell, S. (1970). Attachment, exploration, and separation: Illustrated by the behavior of oneyear-olds in a strange situation. Child Development, 41, 49-67.

Ainsworth, M. D. S., Blehar, M. C., Waters, E., \& Wall, S. N. (1978). Patterns of attachment: a psychological study of the strange situation. Hillsdale, Lawlence Erlbaum Associates.

Ainsworth, M. D. S., Blehar, M. C., Waters, E., \& Wall, S. N. (2015). Patterns of attachment: A psychological study of the strange situation. London: Psychology Press.

Andangsari, E., Gumilar, I., \& Godwin, R. (2013). Social networking sites uses and psychological attachment need among Indonesian young adults population. International Journal of Social Science Studies, 1, 133-138.

Andreassen, C. S., Torsheim, T., Brunborg, G. S., \& Pallesen, S. (2012). Development of a Facebook addiction scale. Psychological Reports, 110(2), 501-517.

Andreassen, C. S., Billieux, J., Griffiths, M., Kuss, D., Demetrovics, Z., \& Mazzoni, E. (2016). The relationships between addictive use of social media and video games and symptoms of psychiatric disorders: A large-scale cross-sectional study. Psychology of Addictive Behaviors, 30(2), 252-262. 
Andreassen, C. S., Pallesen, S., \& Griffiths, M. D. (2017). The relationship between excessive online social networking, narcissism, and self-esteem: Findings from a large national survey. Addictive Behaviors, 64, 287-293.

Armsden, G., \& Greenberg, M. (1987). The inventory of parent and peer attachment: Individual differences and their relationships to psychological well-being in adolescence. Journal of Youth and Adolescence, 16(5), 427-454.

Armsden, G. C., \& Greenberg, M. T. (1989). Inventory of parent and peer attachment (IPPA). Washington, WA: University of Washington Seattle.

Assunção, R., Costa, P., Tagliabue, S., \& Matos, P. (2017). Problematic Facebook use in adolescents: Associations with parental attachment and alienation to peers. Journal of Child and Family Studies, 26(11), 2990-2998.

Bartholomew, K., \& Horowitz, L. (1991). Attachment styles among young adults: A test of a four-category model. Journal of Personality and Social Psychology, 61(2), 226-244.

Bashir, S., Malik, J., \& Mansoor, S. (2017). Involvement and communication on face book: Exploring interaction patterns of personality and adult attachment styles. Pakistan Business Review, 19(1), 233-250.

Becoña, I., del Elena, F., Amador, C., \& Ramón, F. (2014). Attachment and substance use in adolescence: A review of conceptual and methodological aspects. Adicciones, 26(1), 77-86.

Behrens, K., Hesse, E., \& Main, M. (2007). Mothers' attachment status as determined by the Adult Attachment Interview predicts their 6-year-olds' reunion responses: A study conducted in Japan. Developmental Psychology, 43(6), 1553-1567.

Beranuy, M., Chamarro, A., Graner, C., \& Carbonell, X. (2009). Validation of two brief scales to assess Internet and mobile phone addictions. Psicothema, 21(3), 480-485.

Blackwell, D., Leaman, C., Tramposch, R., \& Osborne, M. (2017). Extraversion, neuroticism, attachment style and fear of missing out as predictors of social media use and addiction. Personality and Individual Differences, 116, 69-72.

Boute, V., Wood, E., \& Pratt, M. (2009). Exploring similarities and differences between online and offline friendships: The role of attachment style. Computers in Human Behavior, 25, 560-567.

Bowlby, J. (1958). The nature of the child's tie to his mother. International Journal of Psycho-Analysis, 39, 350373.

Bowlby, J. (1969). Attachment, vol. 1 of Attachment and loss. London: Hogarth Press.

Bowlby, J. (1973). Separation: anxiety and anger, vol. 2 of Attachment and loss. London: Hogarth Press.

Bowlby, J. (1979). The making and breaking of affectional bonds. New York: Basic Books.

Bowlby, J. (1982). Attachment (second edition of Vol 1) of Attachment and loss. London: Hogarth Press.

Bowlby, J. (1988). A secure base: clinical applications of attachment theory (collected papers). London: Tavistock.

Brennan, K. A., Clark, C. L., \& Shaver, P. R. (1998). Self-report measurement of adult romantic attachment: an integrative overview. In J. A. Jimpson \& W. S. Rholes (Eds.), Attachment theory and close relationships (pp. 46-76). New York: The Guildford.

Brown, R. I. F. (1993). Some contributions of the study of gambling to the study of other addictions. In W. R. Eadington \& J. Cornelius (Eds.), Gambling behavior and problem gambling (pp. 241-272). Reno, NV: University of Nevada Press.

Ceyhan, E., Ceyhan, A. A., \& Gürcan, A. (2007). The validity and reliability of the problematic internet usage scale. Educational Sciences: Theory \& Practice, 7(1), 411-416.

Charlton, J. P., \& Danforth, I. D. W. (2010). Validating the distinction between computer addiction and engagement: Online game playing and personality. Behaviour \& Information Technology, 29(6), 601-613.

Chen, S. H., Weng, L. J., Su, Y. J., Wu, H. M., \& Yang, P. F. (2003). Development of a Chinese internet addiction scale and its psychometric study. Chinese Journal of Psychology, 45(3), 279-294.

Cohen, L. (1974). The operational definition of human attachment. Psychological Bulletin, 81, 207-217.

Collins, N. L., \& Read, S. J. (1990). Adult attachment, working models, and relationship quality in dating couples. Journal of Personality and Social Psychology, 58(4), 644-663.

Dozier, M., Stovall-McClough , K., \& Albus , K. (1998). In Cassidy, J., \& Shaver, P. R. (Eds.). Attachment and psychopathology in adulthood. Handbook of attachment theory and research (pp. 718-744). New York: Guilford.

Eichenberg, C., Schott, M., Decker, O., \& Sindelar, B. (2017). Attachment style and internet addiction: An online survey. Journal of Medical Internet Research, 19(5), e170.

Ellison, N. B., Steinfield, C., \& Lampe, C. (2007). The benefits of Facebook friends' social and college students' use of online social network sites. Journal of Computer-Mediated Communication, 12, 1143-1168.

Eroglu, Y. (2015). Interrelationship between attachment styles and Facebook addiction. Journal of Education and Training Studies, 4(1), 150-160.

Estévez, A., Jáuregui, P., Sánchez-Marcos, I., López-González, H., \& Griffiths, M. (2017). Attachment and emotion regulation in substance addictions and behavioral addictions. Journal of Behavioral Addictions, 6(4), 534-544. 
Feeney, J. A., Noller, P., \& Hanrahan, M. (1994). Assessing adult attachment. In M. B. Sperling \& W. H. Berman (Eds.), Attachment in adults: clinical and developmental perspectives (pp. 128-152). New York: Guilford Press.

Ferreira, M., \& Costa, M. E. (1998). Inventory of peer and parental attachment. Adaptação do instrumento. Manuscrito não publicado. Faculdade de Psicologia e de Ciências da Educação da Universidade do Porto.

Fioravanti, G., \& Casale, S. (2015). Evaluation of the psychometric properties of the Italian internet addiction test. Cyberpsychology, Behavior and Social Networking, 18(2), 120-128.

Flores, P. (2004). Addiction as an attachment disorder. New York: Jason Aronson Inc.

Fossati, A., Feeney, J. A., Donati, D., Domini, N., Novella, L., et al. (2003). On the dimensionality of the attachment style questionnaire in Italian clinical and nonclinical participants. Journal of Social Personal Relationships, 20(1), 50-79.

Fraley, R. C., Waller, N. G., \& Brennan, K. A. (2000). An item response theory analysis of self-reports measures of adult attachment. Journal of Personality and Social Psychology, 78, 350-365.

Fujimori, A., Yamazaki, T., Sato, M., Hayashi, H., Fujiwara, Y., \& Matsusaka, T. (2015). Study on influence of internal working models and gender differences on addiction of social network sites in Japanese university students. Psychology, 6(14), 1832-1840.

Griffin, D. W., \& Bartholomew, K. (1994). The metaphysics of measurement: the case of adult attachment. In K. Bartholomew \& D. Perlman (Eds.), Advances in personal relationships: attachment processes in adulthood (pp. 17-52). London: Kingsley.

Griffiths, M. D. (1996a). Internet addiction: An issue for clinical psychology? Clinical Psychology Forum, 97, 32-36.

Griffiths, M. D. (1996b). Behavioural addictions: an issue for everybody? Journal of Workplace Learning, 8(3), $19-25$.

Griffiths, M. D. (2000). Internet addiction - Time to be taken seriously? Addiction Research, 8(5), 413-418.

Griffiths, M. D. (2005). A 'components' model of addiction within a biopsychosocial framework. Journal of Substance Use, 10, 191-197.

Griffiths, M. D., Pontes, H., \& Kuss, D. (2016). Online addictions: Conceptualization, debates and controversies. Addicta: The Turkish Journal on Addictions, 3(2), 151-164.

Hambleton, R. K., Merenda, P. F., Spielberger, C. D. (Eds.) (2005). Adapting educational and psychological tests for crosscultural assessment (pp. 3-38). Mahwah, NJ: Erlbaum.

Harlow, H., \& Zimmermann, R. (1959). Affectional responses in the infant monkey. Science, 130(3373), 421-432.

Hart, J., Nailling, E., Bizer, G., \& Collins, C. (2015). Attachment theory as a framework for explaining engagement with Facebook. Personality and Individual Differences, 77, 33-40.

Hazan, C., \& Shaver, P. (1987). Romantic love conceptualized as an attachment process. Journal of Personality and Social Psychology, 52(3), 511-524.

Ho, S. S., Lwin, M. O., \& Lee, E. W. (2017). Till logout do us part? Comparison of factors predicting excessive social network sites use and addiction between Singaporean adolescents and adults. Computers in Human Behavior, 75, 632-642.

Höfler, D., \& Kooyman, M. (1996). Attachment transition, addiction and therapeutic bonding - An integrative approach. Journal of Substance Abuse Treatment, 13(6), 511-519.

Höger, D., \& Buschkämper, S. (2002). Der Bielefelder Fragebogen zu Partnerschaftserwartungen. Zeitschrift fuer Differentielle und Diagnostische Psychologie, 23, 83-89.

Hughes, D. J., Rowe, M., Batey, M., \& Lee, A. (2012). A tale of two sites: Twitter vs. Facebook and the personality predictors of social media usage. Computers in Human Behavior, 28, 561-569.

Hwang, K. O. (2001). The relationship between attachment style, identity, and interpersonal relation tendency of university students. Master's thesis. In Graduate School of Wonkwang University. Korea: Iksan.

Jenkins-Guarnieri, M., Wright, S., \& Hudiburgh, L. (2012). The relationships among attachment style, personality traits, interpersonal competency, and Facebook use. Journal of Applied Developmental Psychology, 33(6), 294-301.

Kandell, J. (1998). Internet addiction on campus: The vulnerability of college students. CyberPsychology \& Behavior, 1(1), 11-17.

Kohut, H. (1971). The analysis of the self. New York: International Universities Press.

Kozan, H., Kesici, S., Buyukbayraktar, C., \& Yalcin, S. (2016). Prediction of problematic internet use by attachment in university students. Journal of Education and Training Studies, 5(1), 79-83.

Kuss, D., \& Griffiths, M. D. (2011). Online social networking addiction - A review of the psychological literature. International Journal of Environmental Research and Public Health, 8(9), 3528-3552.

Kuss, D. J., \& Griffiths, M. D. (2017). Social networking sites and addiction: Ten lessons learned. International Journal of Environmental Research and Public Health, 14, 311.

Kuss, D. J., Griffiths, M. D., Karila, L., \& Billieux, J. (2014). Internet addiction: A systematic review of epidemiological research for the last decade. Current Pharmaceutical Design, 20, 4026-4052. 
La Barbera, D., La Paglia, F., \& Valsavoia, R. (2009). Social network and addiction. Cyberpsychology \& Behavior, 12, 628-629.

Lei, L., \& Wu, Y. (2007). Adolescents' paternal attachment and Internet use. CyberPsychology \& Behavior, 10(5), 633-639.

Lei, L., \& Yang, Y. (2007). The development and validation of adolescent pathological Internet use scale. Acta Psychologica Sinica, 39(4), 688-696.

Lin, J. (2015). The role of attachment style in Facebook use and social capital: Evidence from university students and a national sample. Cyberpsychology, Behavior and Social Networking, 18(3), 173-180.

Lin, J. H. (2016). Need for relatedness: A self-determination approach to examining attachment styles, Facebook use, and psychological well-being. Asian Journal of Communication, 26(2), 153-173.

Liu, H., Shi, J., Liu, Y., \& Sheng, Z. (2013). The moderating role of attachment anxiety on social network site use intensity and social capital. Psychological Reports, 112(1), 252-265.

Longstreet, P., \& Brooks, S. (2017). Life satisfaction: A key to managing internet \& social media addiction. Technology in Society, 50, 73-77.

Longua Peterson, J., Giguere, B., \& Sherman, J. (2017). Social connection and social networking: Daily conflict increases nightly Facebook use among avoidant participants. Self and Identity, 16(2), 215-230.

Main, M., \& Solomon, J. (1990). Procedures for identifying infants as disorganized/disoriented during the Ainsworth Strange Situation. In M. T. Greenberg, D. Cicchetti, \& E. M. Cummings (Eds.), Attachment in the preschool years (pp. 121-160). Chicago: University of Chicago Press.

Matos, P. M., \& Costa, M. E. (2001). The Father and Mother Attachment Questionnaire: Revised version. Faculty of Psychology and Education, University of Porto, Portuga: Unpublished manuscript.

Mazaheri Nejadfard, G., \& Hosseinsabet, F. (2017). Predicting internet addiction based on sensation seeking: Mediation effect of attachment styles. Practice in Clinical Psychology, 5(3), 195-202.

McLeod, S. (2008). Mary Ainsworth. Retrieved May 27, 2018, from http://www.simplypsychology.org/maryainsworth.html

Mikulincer, M., \& Shaver, P. (2007). Attachment in adulthood: Structure, dynamics, and change. New York: Guilford Press.

Monacis, L., de Palo, V., Griffiths, M. D., \& Sinatra, M. (2016). Validation of the Internet Gaming Disorder Scale-Short-Form (IGDS9-SF) in an Italian-speaking people. Journal of Behavioral Addictions, 5, 683-690.

Monacis, L., de Palo, V., Griffiths, M., \& Sinatra, M. (2017a). Exploring individual differences in online addictions: The role of identity and attachment. International Journal of Mental Health and Addiction, 15(4), 853-868.

Monacis, L., De Palo, V., Griffiths, M. D., \& Sinatra, M. (2017b). Social networking addiction, attachment style, and validation of the Italian version of the Bergen Social Media Addiction Scale. Journal of Behavioral Addictions, 6(2), 178-186.

Morey, J., Gentzler, A., Creasy, B., Oberhauser, A., \& Westerman, D. (2013). Young adults' use of communication technology within their romantic relationships and associations with attachment style. Computers in Human Behavior, 29(4), 1771-1778.

Müller, K. W., et al. (2013). Prevalence of internet addiction in the general population: results from a German population-based survey. Behavior and Information Technology, 33(7), 757-766.

Obegi, J., \& Berant, E. (2010). In J. H. Obegi \& E. Berant (Eds.), Attachment theory and research in clinical work with adults (pp. 18-26). New York: Guilford Press.

Odacı, H., \& Çıkrıkçı, Ö. (2014). Problematic internet use in terms of gender, attachment styles and subjective well-being in university students. Computers in Human Behavior, 32, 61-66.

Oldmeadow, J., Quinn, S., \& Kowert, R. (2013). Attachment style, social skills, and Facebook use amongst adults. Computers in Human Behavior, 29(3), 1142-1149.

Orr, E., Sisic, M., Ross, C., Simmering, M., Arsenault, J., \& Orr, R. (2009). The influence of shyness on the use of Facebook in an undergraduate sample. Cyberpsychology, Behavior and Social Networking, 12, 337-340.

Pontes, H. M., \& Griffiths, M. D. (2016). Portuguese validation of the Internet Gaming Disorder Scale-ShortForm. Cyberpsychology, Behavior and Social Networking, 19, 288-293.

Przybylski, A., Murayama, K., DeHaan, C., \& Gladwell, V. (2013). Motivational, emotional, and behavioral correlates of fear of missing out. Computers in Human Behavior, 29(4), 1841-1848.

Rao, G., \& Madan, A. (2012). A study exploring the link between attachment styles and social networking habits of adolescents in urban Bangalore. International Journal of Scientific and Research Publications, 3(1), 1-12.

Reiner, I., Tibubos, A., Hardt, J., Müller, K., Wölfling, K., \& Beutel, M. (2017). Peer attachment, specific patterns of internet use and problematic internet use in male and female adolescents. European Child \& Adolescent Psychiatry, 26(10), 1257-1268.

Reis, H. T., Sheldon, K. M., Gable, S. L., Roscoe, J., \& Ryan, R. M. (2000). Daily well-being: the role of autonomy, competence, and relatedness. Personality and Social Psychology Bulletin, 26(4), 419-435. 
Rom, E., \& Alfasi, Y. (2014). The role of adult attachment style in online social network affect, cognition, and behavior. Journal of Psychology and Psychotherapy Research, 1(1), 24-34.

Ross, C., Orr, E. S., Arseneault, J. M., Simmering, M. G., \& Orr, R. R. (2009). Personality and motivations associated with Facebook use. Computers in Human Behavior, 25, 578-586.

Saucier, G. (1994). Mini-markers: A brief version of Goldberg's unipolar Big-Five markers. Journal of Personality Assessment, 65, 506-516.

Savc1, M., \& Aysan, F. (2016). The role of attachment styles, peer relations, and affections in predicting Internet addiction. Addicta: The Turkish Journal on Addictions, 3(3), 401-432.

Schaffer, H., \& Emerson, P. (1964). The development of social attachments in infancy. Monographs of the Society for Research in Child Development, 29(3), 1-77.

Schimmenti, A., Passanisi, A., Gervasi, A., Manzella, S., \& Famà, F. (2014). Insecure attachment attitudes in the onset of problematic Internet use among late adolescents. Child Psychiatry \& Human Development, 45(5), 588-595.

Şenormanc1, Ö., Șenormanc1, G., Güçlü, O., \& Konkan, R. (2014). Attachment and family functioning in patients with internet addiction. General Hospital Psychiatry, 36(2), 203-207.

Shin, S., Kim, N., \& Jang, E. (2011). Comparison of problematic internet and alcohol use and attachment styles among industrial workers in Korea. Cyberpsychology, Behavior and Social Networking, 14(11), 665-672.

Soh, P., Charlton, J., \& Chew, K. (2014). The influence of parental and peer attachment on Internet usage motives and addiction. First Monday, 19(7). Retrieved April 10, 2019, from http://www.ojphi.org/ojs/index. $\mathrm{php} / \mathrm{fm} / \mathrm{article} / \mathrm{view} / 5099$.

Song, M. J. (2000). Internet addictive users' communicative satisfaction in online and offline situation. Master's thesis. Graduate School of Korea University. Korea: Seoul.

Soper, W. B., \& Miller, M. J. (1983). Junk-time junkies: An emerging addiction among students. School Counselor, 31(1), 40-43.

Statista (2017). Daily time spent on social networking by internet users worldwide from 2012 to 2017 (in minutes). Retrieved April 10, 2019, from: https:/www.statista.com/statistics/433871/daily-social-mediausage-worldwide/ .

Tang, J., Chen, M., Yang, C., Chung, T., \& Lee, Y. (2016). Personality traits, interpersonal relationships, online social support, and Facebook addictions. Telematics and Informatics, 33(1), 102-108.

Toda, K. (1988). Basic interpersonal relationships and attachment style in the late adolescence-examination from working models. 52nd Conference of the Japanese Psychological Association (p.57). Hiroshima: Japanese Psychological Association.

Valizadeh, M., Motazedian, S., Kuchi, M., \& Alipoor, R. (2017). Investigating the relationship between attachment styles and addiction severity. Bali Medical Journal, 6(2), 308-313.

Vignoli, E., \& Mallet, P. (2004). Validation of a brief measure of adolescent's parent attachment based on Armsden and Greenberg's three - dimension model. Revue Européène de Psychologie Appliquée, 54(4), $251-260$.

Weinraub, M., Brooks, J., \& Lewis, M. (1977). The social network: A reconsideration of the concept of attachment. Human Development, 20(1), 31-47.

Wilson, H., Fornasier, S., \& White, K. (2010). Psychological predictors of young adult's use of social networking sites. Cyberpsychology, Behavior and Social Networking, 12, 337-340.

Wölfling, K., Müller, K. W., \& Beutel, M. E. (2010). Skala zum Onlinesuchtverhalten (OSV-S). In D. Muecken, A. Teske, \& F. Rehbein (Eds.), Prävention, diagnostik und therapie von computerspielabhängigkeit. Lengerich: Pabst Science Publisher.

World Health Organization. (2011). Global status report on alcohol and health. Geneva: World Health Organization.

Yaakobi, E., \& Goldenberg, J. (2014). Social relationships and information dissemination in virtual social network systems: An attachment theory perspective. Computers in Human Behavior, 38, 127-135.

Yang, X., Zhu, L., Chen, Q., Song, P., \& Wang, Z. (2016). Parent marital conflict and internet addiction among Chinese college students: The mediating role of father-child, mother-child, and peer attachment. Computers in Human Behavior, 59, 221-229.

Young, K. S. (1998). Internet addiction: The emergence of a new clinical disorder. CyberPsychology \& Behavior, $1,237-244$.

Publisher's Note Springer Nature remains neutral with regard to jurisdictional claims in published maps and institutional affiliations. 